\title{
DESSULFURAÇÃO DO AÇO EM DESGASEIFICADOR RH POR MEIO DE MODELO MATEMÁTICO*
}

\author{
Lucas Teixeira Costa ${ }^{1}$ \\ Roberto Parreiras Tavares ${ }^{2}$
}

\section{Resumo}

Um modelo matemático foi criado para simular a dessulfuração do aço no desgaseificador $\mathrm{RH}$ na condição de uma camada de escória sobrenadante adicionada dentro da câmara de vácuo após a subida do aço sob efeito da pressão. Tomou-se como base o modelo físico do LaSiP (Laboratório de Simulação de Processos) em escala 1:5 para a instalação industrial de uma usina brasileira. A validação do modelo foi realizada por meio da taxa de circulação do modelo físico e de sua simulação. A dessulfuração do aço foi realizada pelo modelo matemático para as condições operacionais da indústria e a avaliação de parâmetros como composição química e volume de escória foram investigadas. Ao final, obteve-se resultados compatíveis com os presentes na literatura e um modelo capaz de prever com grande confiabilidade a evolução do teor de enxofre ao longo do processo de dessulfuração. Considera-se, portanto que a prática de remoção de enxofre no $\mathrm{RH}$ é viável e tem-se uma rota adicional/alternativa ao forno panela.

Palavras-chave: Dessulfuração; $\mathrm{Aço;} \mathrm{RH}$; Modelo matemático.

\section{A CFD MODEL TO SIMULATION OF STEEL DESULPHURIZATION IN RH DEGASSER}

\section{Abstract}

A mathematical model was set-up to simulate and investigate the desulfurization process on the $\mathrm{RH}$ degasser. It was considered a top slag layer over steel, added at the vacuum chamber after the gas hold-up. The model was built considering the LaSiP (Process Simulation Laboratory) scaled 1:5 model of a industrial brazilian plant. The model validation was performed through circulation rate of the water model and mathematical 1:5 model. The steel desulfurization was carried out in the CFD model for the industrial conditions and some parameters such chemical composition and slag volume were investigated. The model came out with consistent results which fits at the literature data and shown a great reliability to predict the sulfur evolution during the process. Therefore, the desulphurization in $\mathrm{RH}$ degasser can be performed at industrial installations whit good gains expectations and a additional/alternative route is now available to the steel production chain.

Keywords: Desulphurization; Steel; RH degasser; CFD.

Engenheiro Metalurgista, Mestre, Doutorando, PPGEM, UFMG, Belo Horizonte, MG, Brasil.

Engenheiro Metalurgista, PhD, Professor Associado, Departamento de Engenharia Metalúrgica e de Materiais, UFMG, Belo Horizonte, MG, Brasil. 


\section{INTRODUÇÃO}

A dessulfuração do aço é etapa fundamental no processo de fabricação do aço. No Brasil e no mundo esse tratamento é amplamente realizado em forno panela porém algumas indústrias têm realizado esse tratamento durante o processo $\mathrm{RH}$.

A prática de remoção de enxofre em reator $\mathrm{RH}$ é recente, tendo seu início nos anos de 1990 [1]. A partir disso, resultados de remoção de enxofre do aço em $\mathrm{RH}$ são divulgados na literatura como uma prática viável e de bons resultados [2-7]. A prática baseia-se na injeção de material dessulfurante à base de cálcio por meio de lança de partículas finas no seio do metal.

A reação de dessulfuração do aço na câmara de vácuo encontra condições termodinâmicas favoráveis ao processo pois apresenta agitação vigorosa e ausência quase completa de oxigênio, não havendo assim reoxidação por meio do contato com o aço.

No presente trabalho, a viabilidade de dessulfuração do aço em reator $\mathrm{RH}$ foi investigada com a proposta de adição do material dessulfurante na superfície do aço, como uma camada sobrenadante. A adição é realizada após a subida do aço provocada pelo vácuo, por meio de calhas presentes no topo da estrutura da câmara de vácuo.

Entende-se também que a necessidade de passagem do aço pelo desgaseificador $\mathrm{RH}$ para ajuste fino da composição química para a descarburação do aço e outros objetivos, justificaria o tratamento para remoção de enxofre nessa mesma estação. A julgar pelos teores finais de enxofre exigidos, há ainda a possibilidade de rota de fabricação sem a passagem do aço no forno panela.

Um modelo matemático foi construído inicialmente em escala laboratorial do modelo físico do LaSiP, Laboratório de Simulação de Processos da UFMG, que toma como base os dados do $\mathrm{RH}$ de uma instalação industrial brasileira, em escala 1:5. A validação da taxa de circulação de água prevista pelo modelo matemático foi feita a partir de medições experimentais já publicadas [8-10]. Uma vez validado, o modelo em escala industrial foi utilizado para simular o processo de dessulfuração do aço com vistas ao estabelecimento das melhores condições operacionais para a dessulfuração do aço.

\section{MATERIAIS E MÉTODOS}

O presente trabalho foi desenvolvido nas seguintes etapas:

Cálculo por modelo matemático da taxa de circulação no modelo físico e validação; Simulação da reação de dessulfuração de aço no processo $\mathrm{RH}$ de desgaseificação a vácuo;

Avaliação da remoção de enxofre a partir de alterações nos parâmetros operacionais do processo $\mathrm{RH}$.

A tabela 1 apresenta as dimensões dos reatores utilizados no presente trabalho para construção do modelo matemático. 
Tabela 1 - Dimensões dos reatores em escala de laboratório e industrial.

\begin{tabular}{cccc}
\hline & Parâmetros & Modelo físico - LaSiP & RH industrial \\
\hline \multirow{4}{*}{ Panela } & Diâmetro topo $(\mathrm{m})$ & 0,720 & 3,600 \\
& Diâmetro fundo $(\mathrm{m})$ & 0,650 & 3,250 \\
& Altura $(\mathrm{m})$ & 0,760 & 3,800 \\
& Nível líquido $(\mathrm{m})$ & 0,680 & 3,400 \\
\cline { 2 - 4 } Câmara de & Diâmetro $(\mathrm{m})$ & 0,410 & 2,050 \\
vácuo & Altura & 0,712 & $\star 3,560$ \\
& Nível líquido $(\mathrm{m})$ & 0,070 & 0,350 \\
& Pressão $(\mathrm{Pa})$ & $\sim 2800$ & $\sim 60$ \\
\cline { 2 - 4 } Pernas & Comprimento $(\mathrm{m})$ & 0,312 & 1,560 \\
& Diâmetro $(\mathrm{m})$ & 0,120 & 0,600 \\
& Imersão $(\mathrm{m})$ & 0,135 & 0,675 \\
& Entre centros $(\mathrm{m})$ & 0,260 & 1,300 \\
\hline
\end{tabular}

*Valor correspondente ao fator de escala, porém, sabe-se que a câmara de vácuo do RH é maior. O modelo está focado em simular o escoamento de aço e escória agitados por gás, assim, não é necessário simular toda a câmara.

\section{1 - Taxa de Circulação}

Os resultados de simulação matemática foram comparados com os valores de taxa de circulação medidos no modelo a frio do LaSiP [8-10]. Duas abordagens foram utilizadas para identificar a melhor forma de validar os resultados, a primeira com a condição de degassing no topo da câmara de vácuo e a segunda com a condição de abertura, sendo nesse caso utilizado uma câmara maior. Esses modelos são chamados no presente trabalho de MM LaSiP 1 e MM LaSiP 2, em que "MM" indica modelo matemático.

A taxa de circulação foi calculada no modelo matemático pelo acompanhamento do volume de matéria passante numa secção transversal da perna de descida para a faixa de vazão de trabalho no laboratório de 100 a $500 \mathrm{~L} / \mathrm{min}$.

\section{2 - Configuração do Modelo de Dessulfuração do Aço}

A dessulfuração do aço foi realizada no modelo matemático trifásico (aço, escória e argônio) de dimensões industriais em duas etapas distintas:

Estado estacionário:

- Equação da continuidade;

- Equação de conservação de quantidade de movimento;

- Equação de conservação de energia cinética turbulenta;

- Equação de conservação da taxa de dissipação de energia cinética de turbulência.

Estado transiente:

- Conservação de espécie - enxofre

Tanto a simulação de escoamento transiente quanto a estacionária aborda aço e escória como fluidos newtonianos, incompressíveis e de viscosidade e densidade constantes. O argônio é abordado como gás ideal e, portanto, o volume varia em função da pressão. Além disso, considerou-se um sistema isotérmico, pois a convecção natural gerada pela diferença de temperatura no meio não tem influência significativa quando comparada à convecção forçada pela entrada e expansão do gás no caminho ascendente.

Condições de não escorregamento foram assumidas nas paredes de todo o reator, excetuando-se o topo do vaso, configurado na condição de escorregamento livre e 
topo da câmara, que assumiu condição de desgaseificação no MM LaSiP 1, e abertura no MM LaSiP 2 e modelo industrial.

As frações volumétricas das fases envolvidas foram calculadas em cada elemento de volume do domínio, o que permite a determinação de contornos e áreas importantes à transferência de massa.

Malhas do tipo não uniforme com cerca de $1.2 \times 10^{6}$ elementos de volume foram utilizadas nos modelos com refinamento diferenciado em regiões de escoamento mais importante como plugues e região interfacial.

O enxofre é introduzido no estado transiente da simulação como uma variável adicional. Dessa forma, ele segue as linhas de fluxo, mas não altera a massa das fases em que ele se encontra e também não altera o escoamento. Considera-se que no início da simulação transiente o enxofre está uniformemente distribuído no aço.

A escória é adicionada no interior da câmara de vácuo como uma camada sobrenadante, ao invés de injeção por finos como visto em trabalhos já referenciados.

\subsection{1 - Abordagem matemática para a transferência de massa}

A dessulfuração do aço é uma reação que ocorre na interface metal-escória. Devido as altas temperaturas envolvidas, a taxa de reação é bem entendida como sendo controlada pela transferência de massa na difusão da espécie química na camada limite. A equação 1 apresenta a forma geral como a transferência de massa é expressa[1]:

Onde

$$
\frac{d C_{S}}{d t}=-k_{S} \frac{A}{V}\left(C_{S, \text { aço }}-\frac{C_{S, e s c o ́ r i a}}{L_{S}}\right)
$$

$\mathrm{C}_{\mathrm{S}}=$ concentração de enxofre no aço $\left(\mathrm{kg} / \mathrm{m}^{3}\right)$,

$\mathrm{t}=$ tempo $(\mathrm{s})$,

$\mathrm{k}_{\mathrm{s}}=$ coeficiente de transferência de massa $(\mathrm{m} / \mathrm{s})$,

$\mathrm{C}_{\mathrm{S} \text {,escória }}=$ concentração de enxofre na escória $\left(\mathrm{kg} / \mathrm{m}^{3}\right)$,

$\mathrm{L}_{S}=$ coeficiente de partição de enxofre escória-metal,

$\mathrm{A}=$ área interfacial,

$\mathrm{V}=$ volume de aço.

Três parâmetros na equação acima, área interfacial, coeficiente de transferência de massa e coeficiente de partição de enxofre são determinados a seguir para que a equação 1 possa ser aplicada para a simulação do processo de remoção de enxofre do aço.

\section{3 - Cálculo da Área Interfacial}

A área interfacial é obtida pela utilização do modelo de superfície livre para resolver o encontro das fases envolvidas no transporte de enxofre. Para pares de fluidos presentes no escoamento multifásico calcula-se a área interfacial por unidade de volume (densidade de área interfacial). A integral volumétrica desta variável, portanto, resultará na área interfacial de todas as unidades de volume em que exista a presença das duas fases escolhidas, nesse caso, aço e escória, equação 2.

$$
A_{T \alpha \beta}=\iiint_{D} A_{\alpha \beta} d v
$$

Onde:

$A_{T \alpha \beta}=$ Área da interface entre metal e escória, $\mathrm{m}^{2}$.

$A_{\alpha \beta}=$ Densidade de área interfacial entre as fases alfa e beta, $1 / \mathrm{m}$;

$D$ = Domínio; 
$d v=$ Elemento infinitesimal de volume;

Tem-se assim a área total em que ocorre encontro entre as fases aço e escória, nessa região haverá a transferência de massa.

\section{4 - Coeficiente de Transferência de Massa}

O coeficiente de transferência de massa foi estimado com base na correlação [11] expressa pela equação 3.

Onde

$$
S h=0,551 \cdot R e^{4 / 5} \cdot S c^{1 / 3}
$$

$S h=$ número de Sherwood, $R e=$ número de Reynolds e $S c=$ número de Schmidt.

O valor do coeficiente de transferência de massa pode ser expresso em termos da velocidade do aço[11] na interface escória-metal, conforme a equação 4:

$$
k_{s}=1,45 \times 10^{-3} \cdot\left[v_{i}\right]^{4 / 5}
$$

Em que $v_{i}=$ velocidade do aço na interface metal-escória, calculado pelo modelo matemático.

\section{5 - Coeficiente de Partição de Enxofre}

A determinação da partição de enxofre que é a relação entre os teores de enxofre da escória e metal no equilíbrio, foi realizada a partir do cálculo da capacidade de enxofre da escória, conforme apresentado por Gaye [12]. A tabela 2 apresenta a composição química de duas escórias e a partição de enxofre.

Tabela 2 - escórias utilizadas nas simulações

\begin{tabular}{cccccc}
\hline Escória & $\% \mathrm{CaO}$ & $\% \mathrm{MgO}$ & $\% \mathrm{SiO}_{2}$ & $\% \mathrm{Al}_{2} \mathrm{O}_{3}$ & $\mathrm{Ls}$ \\
\hline $\mathrm{Ls}_{1}$ & 54 & 5 & 19 & 22 & $\sim 50$ \\
$\mathrm{Ls}_{2}$ & 57 & 8 & 10 & 25 & $\sim 140$ \\
\hline
\end{tabular}

\section{RESULTADOS E DISCUSSÃO}

Os resultados e respectivas discussões são apresentados na ordem proposta na metodologia do trabalho.

\section{1 - Cálculo da Taxa de Circulação para Validação do Mdelo Matemático}

A figura 1 apresenta a taxa de circulação do modelo físico com os intervalos de confiança superiores e inferiores [8-10] comparados aos resultados previstos pelos dois modelos matemáticos (MM LaSiP 1 e 2), apresentados na figura 2. 


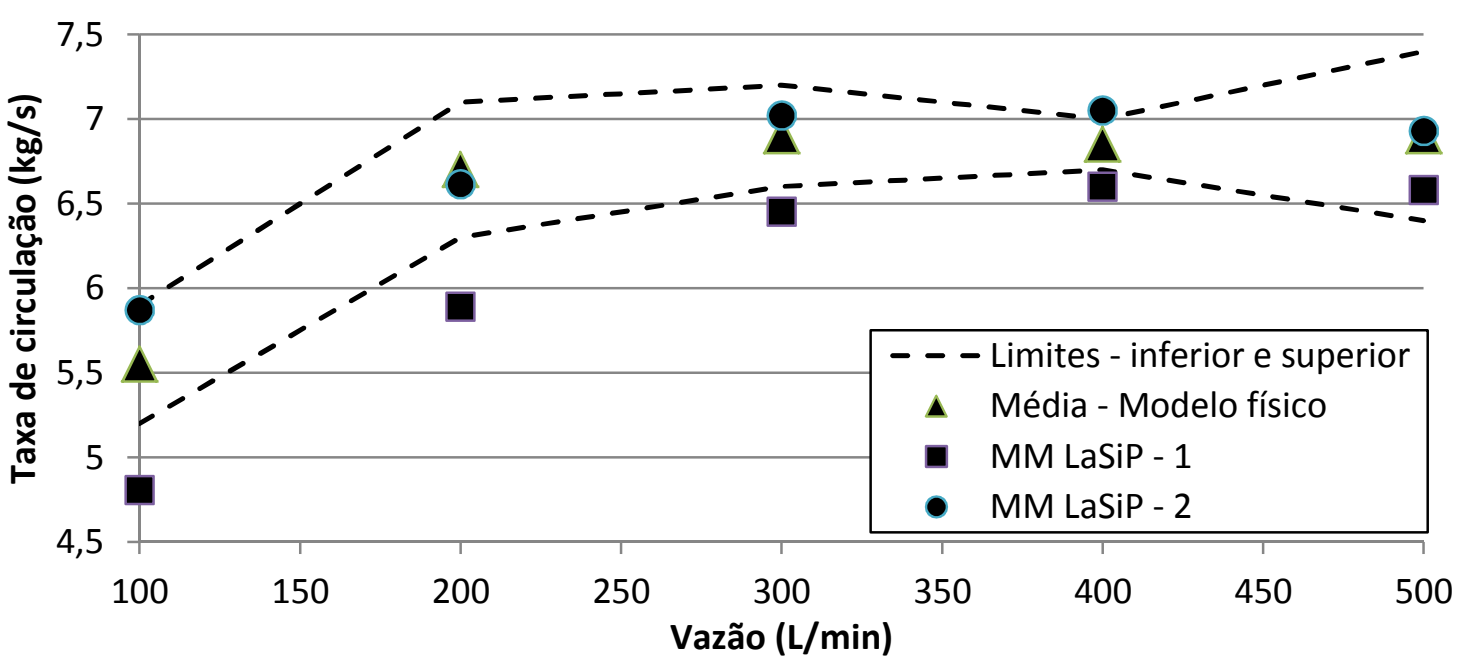

Figura 1 - Comparação da taxa de circulação medida e calculada para diferentes vazões.
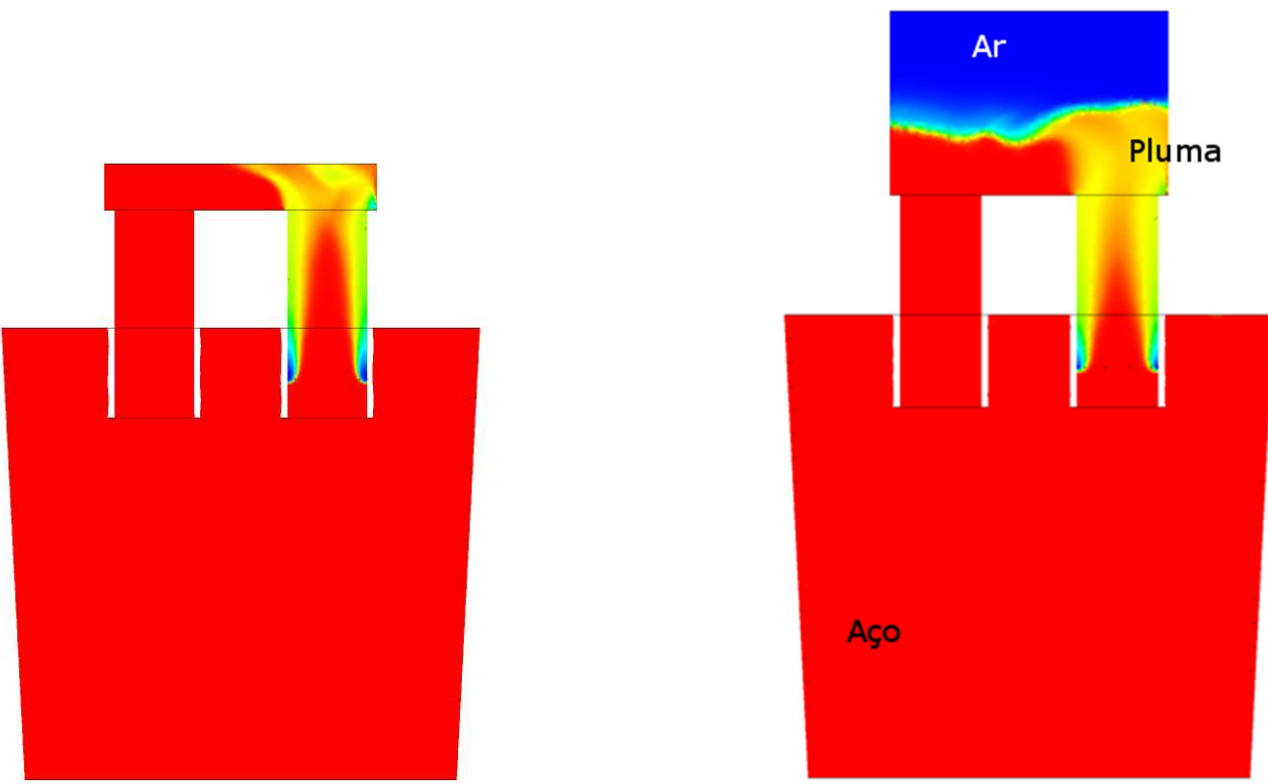

Figura 2 - MM LaSiP nas configurações 1, degassing, e 2, abertura no topo da camara de vácuo.

Os resultados da figura 1 indicam que a simulação do $\mathrm{RH}$ com a câmara de vácuo inteira (MM LaSiP 2) e não cortada (MM LaSiP 1) respondeu melhor ao comportamento observado no modelo físico, o que justifica o aumento do custo computacional.

Os campos de velocidade na cor vermelha para maiores velocidades e azul para valores mais baixos, e vetores que representam o sentido do fluxo com tamanho variável em função da velocidade são apresentados na figura 3. 

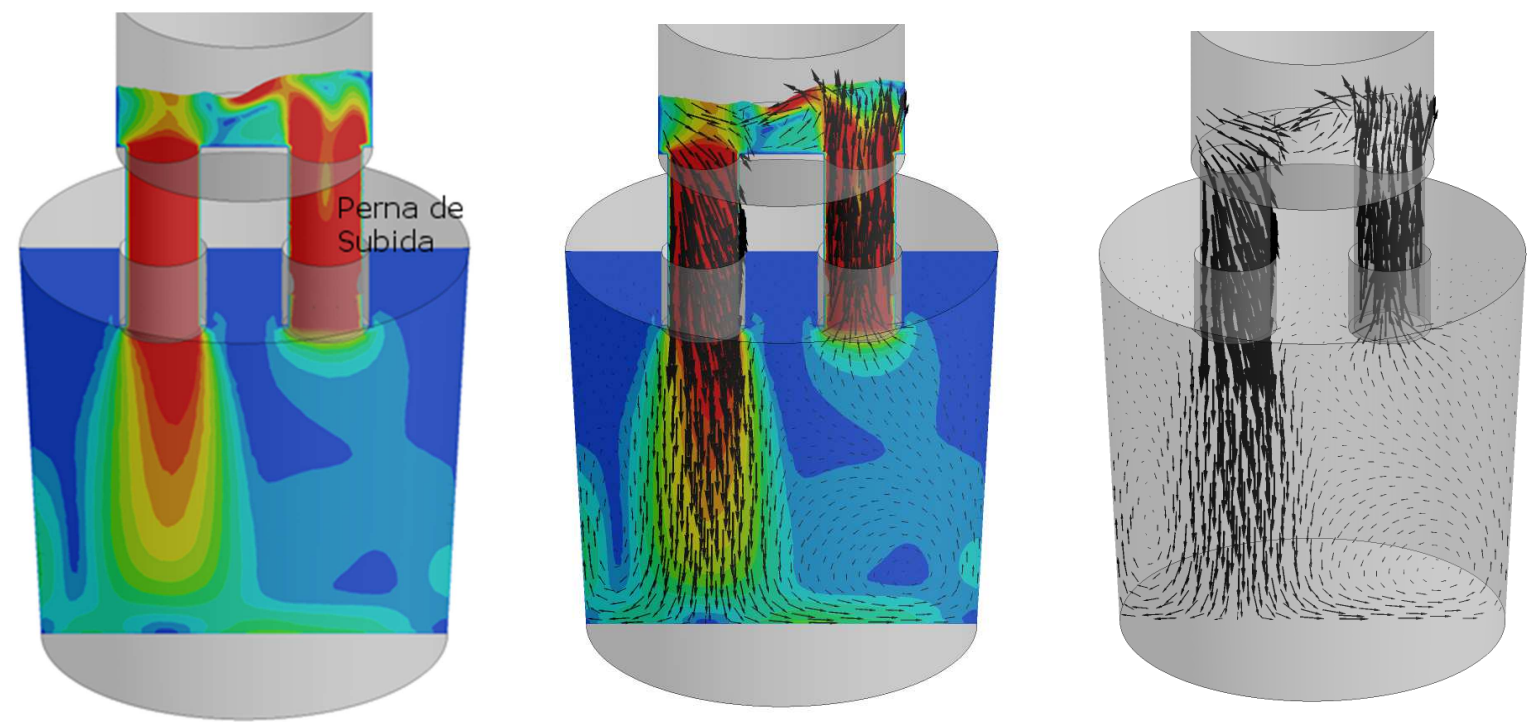

Figura 3 - Campos de velocidade do $\mathrm{RH}$ em funcionamento.

\section{2 - Modelo de Dessulfuração de Aço}

A figura 4 apresenta o perfil do modelo trifásico do $\mathrm{RH}$ em tamanho real e a trajetória de uma partícula durante 1 minuto no reator em funcionamento.
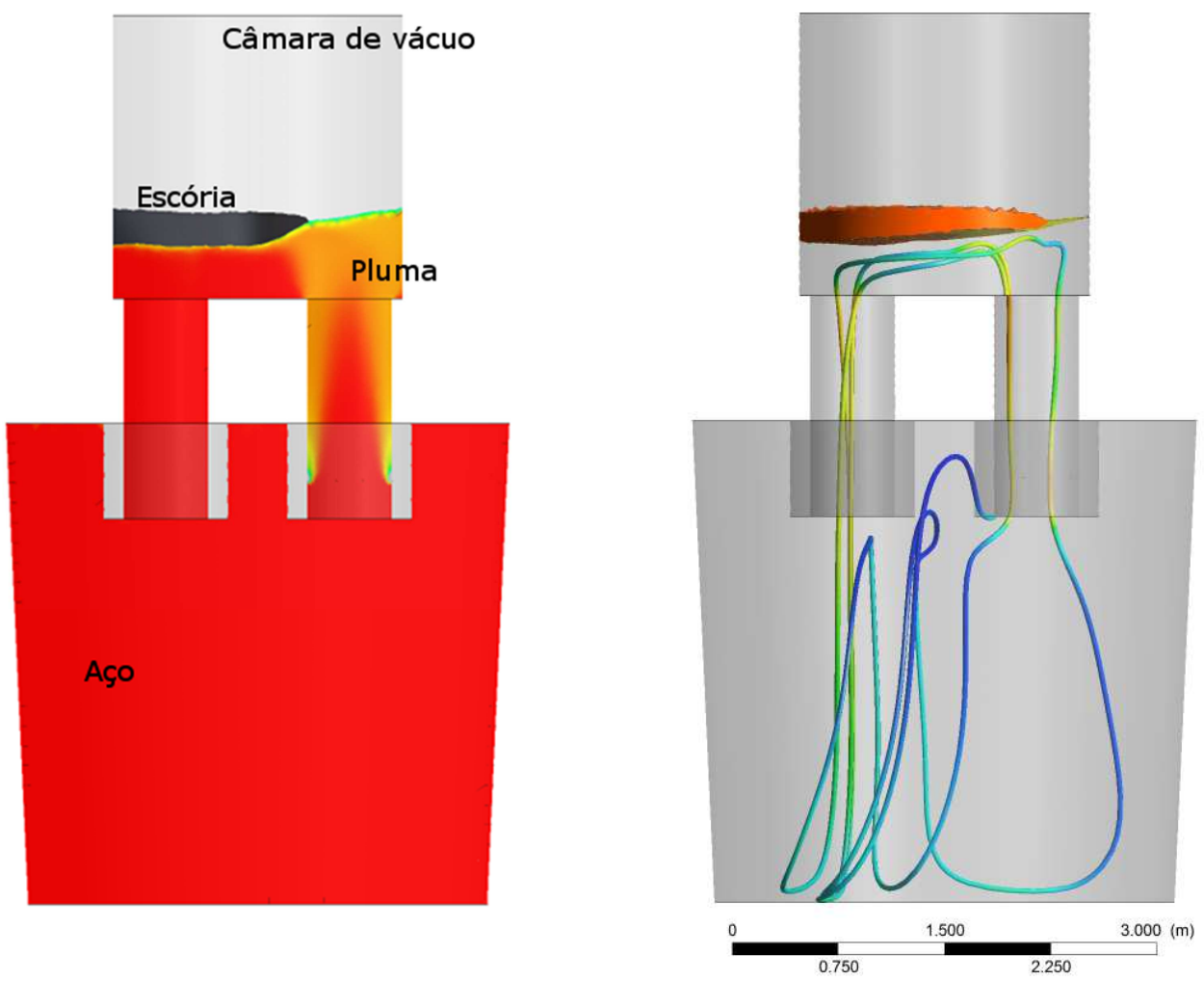

Figura 4 - Perfil de fases e trajetória de uma partícula genérica no modelo.

O modelo matemático do reator industrial foi simulado com vazão de argônio da ordem de $100 \mathrm{Nm}^{3} / \mathrm{h}$, que adequa-se ao meio da faixa de trabalho apresentada por [10], para esse reator na indústria. A taxa de circulação calculada também é semelhante à da planta, da ordem de $130 \mathrm{t} / \mathrm{min}$. 
A região em que haverá a transferência de massa no modelo é apresentada na figura 5:
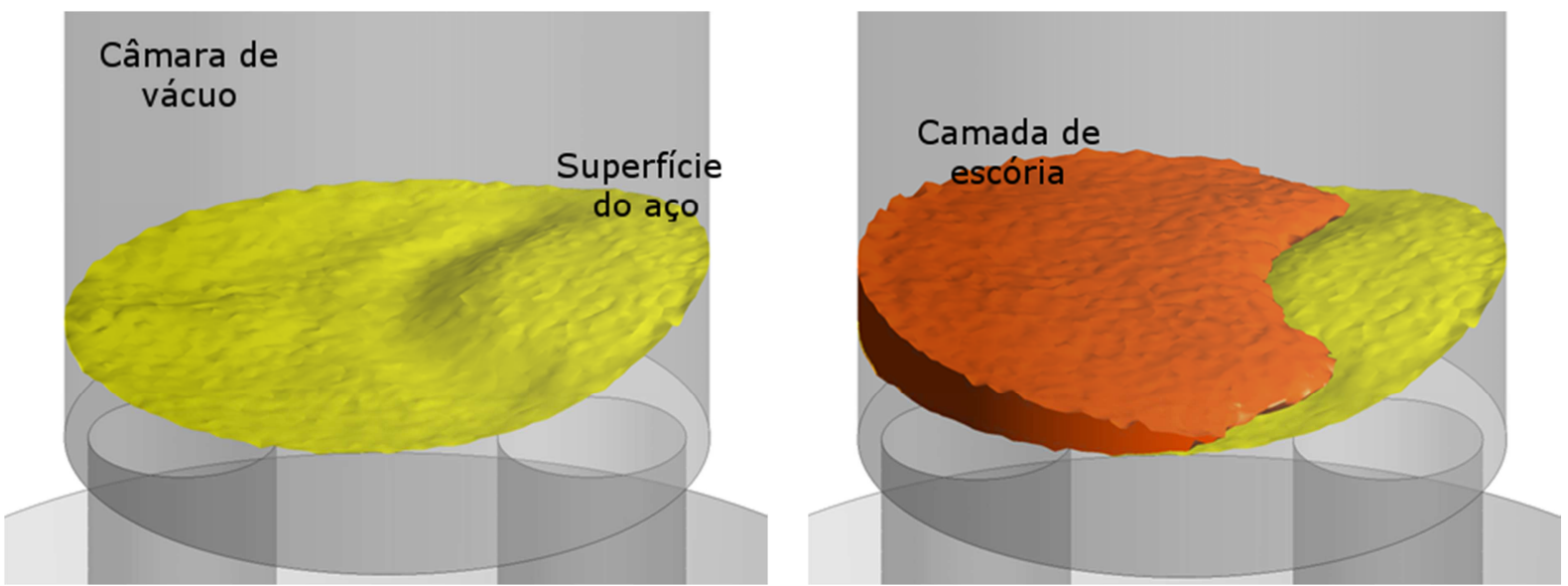

Figura 5 - Superfície do aço exposta e recoberta com escória dentro da câmara de vácuo.

A partir da figura 5, pode-se perceber que a reação de dessulfuração ocorrerá na área de contato, calculada pelo modelo, entre as camadas de aço e escória apresentadas.

\section{3 - Previsão da Dessulfuração e Avaliação de Parâmetros termodinâmicos}

A figura 6 apresenta o resultado comparativo de tratamento de dessulfuração em forno panela com o RH. Para ambos os casos, utilizou-se a mesma composição e peso de escória (18kg/t aço), logo, o enxofre removido será o mesmo. Além disso, a concentração inicial de enxofre no metal e na escória foram mantidas iguais nos dois casos.

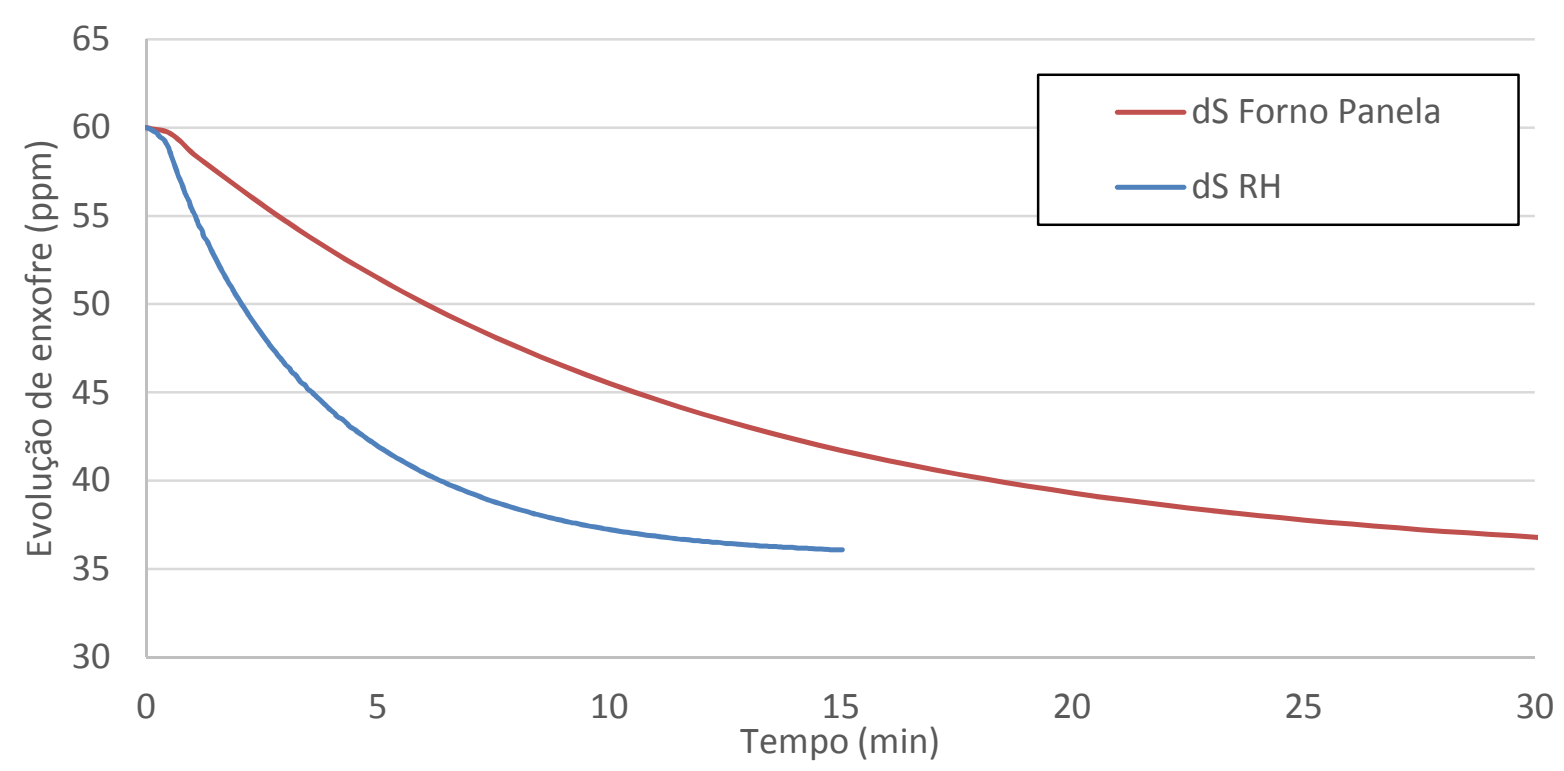

Figura 6 - Comparativo da evolução de enxofre em Forno Panela e RH

Como as condições de tratamento foram igualadas, tem-se o enxofre final semelhante e por isso a comparação de tempo é válida. 
O ambiente de maior agitação proporcionado no $\mathrm{RH}$ favorece a reação de dessulfuração que considera a velocidade do aço na interface metal-escória como fator determinante para uma maior ou menor resposta na transferência de massa.

Com base nesses resultados, foram propostas algumas mudanças no tratamento como aumento do volume de escória, mudança de sua composição química e o efeito combinado dessas alterações, como pode ser visto na figura 7 .

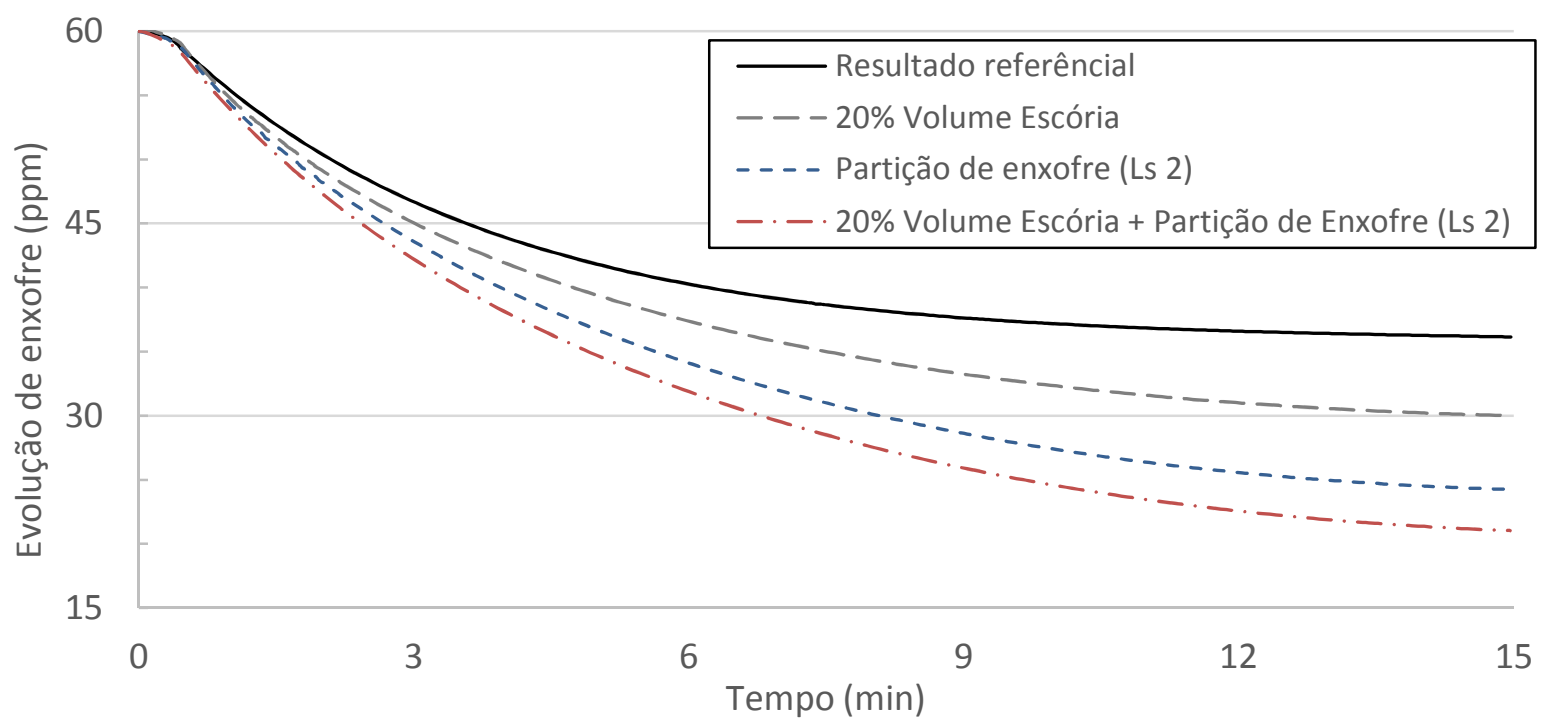

Figura 7 - Efeito de parâmetros no resultado da dessulfuração em $\mathrm{RH}$.

Nota-se que os resultados de dessulfuração variaram entre 40 e $67 \%$ de eficiência tomando-se os teores iniciais e finais de enxofre nas diferentes condições de tratamento. Esses valores são compatíveis com os referenciados e também de práticas industriais.

Para aços vindos com teores mais altos, pode-se promover duas etapas de tratamento no $\mathrm{RH}$, com adição da escória na câmara de vácuo acontecendo em momentos sucessivos.

\section{CONCLUSÃO}

O presente trabalho permite concluir que o tratamento de dessulfuração de aço em RH pela adição da escória como uma camada sobrenadante na câmara de vácuo é eficiente, variando de 40 a $67 \%$ de dessulfuração. Valores mais expressivos podem ser obtidos ao utilizar escórias com maior capacidade de enxofre e adição de $\mathrm{CaF}_{2}$, por exemplo.

A boa representação do modelo físico permite dizer que os resultados do modelo matemático para a instalação industrial indicam que a utilização do processo $\mathrm{RH}$ como opção para o tratamento de dessulfuração do aço apresenta perspectivas de bons resultados.

\section{Agradecimentos}

CNPq pela bolsa de doutorado concedida, processo 140893/2012-1

FAPEMIG pelo apoio financeiro no projeto PPM-00118-13: Modelagens física e matemática do escoamento multifásico em reatores metalúrgicos. 


\section{REFERÊNCIAS}

1 Z. Zulhan, C. Schrade, Y. Patriona, Desulphurization of Molten Steel in RH-Degasser by Powder Blowing to Produce Non Grain Oriented (NGO) Silicon Steel. 2013 SEAISI Conference and Exhibition, Session 6A-6, Pattaya - Thailand, 4th June 2013

2 Zhang, G. Wang, Desulphurisation Process in RH Degasser for Soft-killed Ultra-lowcarbon Electrical Steels - ISIJ International, Vol. 52 (2012), No. 6

3 www.baosteel.com/english_n/e07technical_n/tech020401, Desulphurization of Pipeline Steel by Blended Mix Addition in RH Degasser, Baosteel Technical Report.

4 H. Okano, K. Tada, S. Fukagawa, Y. Tajiri, Development of Technology for Producing Ultra Low Sulphur Steel by RH Powder Top Blowing Method, Sumitomo Metal Industries, 1997.

5 N. Van Poucke, Use of the MESID Lance in the RH-Degasser at the Sidmar Steel Plant, 4th European Oxygen Steelmaking Conference (EOSC), Austria, 12-15 May 2003.

6 W. van der Knopp, W. Tiekink, Desulphurization during $\mathrm{RH}$ Treatment at Hoogovens Staal, La Revue de Metallurgie - CIT, Avril 1996.

7 Y. Okada, S. Fukagawa, K. leda, K. Maya, H. Ikemiya, K. Shinme, Development of RH Powder Top Blowing Process, La Revue de Metallurgie - CIT, Juin 1994.

8 Neves; L. Avaliação dos efeitos da injeção de gás na câmara de vácuo do modelo físico de um desgaseificador RH. Dissertação de Mestrado em metalurgia extrativa; UFMG; Belo Horizonte; 2008.

9 Nascimento, A. A.; tavares, R. P. Estudo da cinética de descarburação e taxa de circulação no modelo físico do desgaseificador $\mathrm{RH}$. In: relatório de iniciação científica, UFMG, Belo Horizonte, setembro, 2007

10 Silva, M. Variação da taxa de descarburação para vários padrões de injeção de argônio na perna de subida do desgaseificador a vácuo $\mathrm{RH}$. Dissertação de Mestrado em metalurgia extrativa; UFMG; Belo Horizonte; 2010.

11 Costa, L. Simulação fluidodinâmica computacional para estudo do tratamento de dessulfuração do aço. Dissertação de Mestrado em metalurgia extrativa; UFMG; Belo Horizonte; 2012.

12 Gaye, H.; Gatellier, C.; Nadif, Riboud, P.; Saleil, J.; Faral, M. (1986) Réaction MétalLaitier et Contrôle De La Composition Des Inclusions Résiduelles en Métallurgie Secondaire. Proceedings of the Clean Steel 3rd, Balatonfüred, Hungary. Institute of Metals. 